\title{
EFFECT OF NON SURGICAL PERIODONTAL THERAPY COMBINED WITH DOXYCYCLINE ON THE LEVELS OF GINGIVAL CREVICULAR FLUID OF NITRIC OXIDE
}

\author{
Moshira A. Mohamed ${ }^{*}$, Mohamed A. Ibrahim*, Osama M. Sayed ${ }^{* * * *}$ and Ahmed A. Khalil ${ }^{* * * *}$
}

\begin{abstract}
Reactive oxygen species (ROS) and antioxidant activity have been involved in pathogenesis of periodontitis and investigated by many studies. Nitric oxide (No) one of ROS plays important role in increase pathogenesis of periodontal disease. Tetracycline derivatives like doxycycline is considered a ROS scavenger. It works as antioxidant, lessen oxidative stress and improve NO bioavailability.
\end{abstract}

\section{INTRODUCTION}

Periodontitis is multifactorial disease caused by the interaction of multiple microbial agents found in the bacterial plaque, host susceptibility, and environmental factors. It results in progressive destruction of the periodontal ligament, alveolar bone with pocket formation, attachment loss and recession ${ }^{(1-3)}$. The detection of oxygen dependent production of reactive oxygen species (ROS) and antioxidant activity involvement in pathogenesis of periodontitis have been investigated by many studies. ROS are oxygen-derived free radicals such as superoxide, hydroxyl, nitric oxide, hydrogen peroxide and hypochlorous acid ${ }^{(4-6)}$. NO is a shortlived, reactive free radical synthesized from the conversion of L-arginine to L-citrulline by nitric oxide synthase (NOS). NO is relatively unstable in the presence of oxygen, so it quickly auto- oxidized to produce nitrogen oxides. Nitrate and nitrite are the stable end products of NO oxidation ${ }^{(7,8)}$. Gingival crevicular fluid (GCF) is an exudate creating from serum and can be collected from the gingival sulcus surrounding natural teeth. The flow of this biological fluid is an essential element for determination of the status of periodontal tissues, which reflects

* Demostrator at Oral Medicine, Diagnosis and Periodontology Department, Faculty of Oral and Dental MedicineNahda University

** Prof. of Oral Medicine, Diagnosis and Periodontology Department, Faculty of Dentistry, Minia University *** Ass. Prof. of Oral Medicine, Diagnosis and Periodontology Department, Faculty of Dentistry, Suez Canal University **** Lecturer of Oral Medicine, Oral Diagnosis and Periodontology Departmement Faculty of Dentistry, Minia University 
the cellular response in the periodontium by the constituents of serum and contributions from the gingival crevice ${ }^{(9-11)}$. Doxycycline is considered the most potent MMP inhibitor of tetracyclines. Doxycycline also work as a ROS scavenger and this may contribute to the improvement of some cardiovascular diseases associated with increased concentrations of ROS. It also lessen oxidative stress and improves nitric oxide (NO) bioavailability ${ }^{(12)}$.

The aim of the present study was to compare the effect of non surgical periodontal therapy alone or combined with doxycycline on the level of nitric oxide in GCF of patients affected by chronic periodontitis.

\section{SUBJECTS AND METHODS}

40 subjects were selected from the out patients clinic of the Oral Medicine, Oral Diagnosis and Periodontology Department -Faculty of Dentistry Minia University and Nahda University.The 40 patients were diagnosed with moderate and advanced chronic periodontitis. 20 volunters healthy subjects were included in the study as a control group. The 60 subjects were grouped into three groups: Group I: 20 subjects received non surgical periodontal therapy consisted of scaling and root planning (SRP)+ doxycycline $100 \mathrm{mg}$ once daily* (for 2 weeks). Group II: 20 subjects received only SRP.Group III: 20 healthy subjects. The inclusion criteria were Chronic periodontitis groups with $\mathrm{PD} \geq 5 \mathrm{~mm}$ and $\mathrm{CAL} \geq 4 \mathrm{~mm}$ in at least two sites, age from 25-55, systematically free patients, Non smoker and no prior use of antibiotics in the last 6 months. The exclusion criteria were allergy to tetracycline, Female patients who are pregnant or of child bearing potential and not utilizing birth control and Immunocompromised patients. The two groups of chronic periodontitis was subjected to non surgical periodontal therapy compromising of three sessions of scaling and root planning for 2 weeks including full mouth supra and sub gingival scaling and root planning using hand instruments and ultrasonic scalers. The pocket depth(PD), clinical attachment loss(CAL), plaque index(PI) and gingival index(GI) were recorded at baseline, day 15 and day 30. Gingival crevicular fluid (GCF) sample was collected from the two groups of chronic periodontitis to determine the inflammatory marker nitric oxide using the absorbent filter paper strips at baseline, day 15 and day30 after treatment. Using scalpel blades,chromatography papers were cut to the dimensions of $2 \times 8 \mathrm{~mm}^{\left({ }^{(13)} \text {. Sampling was }\right.}$ collected from the deepest probing site, taken from 3 sites.

After isolation and drying of the test site, presterilized filter paper strips was held in place for 30 seconds $^{(\mathbf{1 4})}$. Then stored in eppendorph tubes at $-20 \mathrm{C}$ until be used for the laboratory analysis. All collected samples of GCF from 3 groups were assayed using (ELISA) technique to assess the level of nitric oxide.

\section{RESULTS}

The mean value of clinical parameters are listed in Table 1. All the clinical parameters were found significantly higher in chronic periodontitis (CP) groups compared to the control group where $(\mathrm{p}<0.001)$

When comparing group 1 to group 2 ,there was improvement in clinical parameters by time from baseline to day 30 .

All the mean values of nitrite, nitrate and nitric oxide levels were higher in $\mathrm{CP}$ groups compared to control group.When comparing group 1 to group 2, there was improvement in nitrite, nitrate and nitric oxide levels by time from baseline to day 30 . 
TABLE (1) Comparison between clinical parameters:

\begin{tabular}{|c|c|c|c|}
\hline Clinical Parameters & Group 1 (SRP+Vibramycin) & Group 2 (SRP) & $\begin{array}{c}\text { Group 3 (Healthy } \\
\text { Control) }\end{array}$ \\
\hline PI Baseline PI Day 15 & $1.65 \pm 0.42$ & $1.64 \pm 0.35$ & $0.16 \pm 0.04$ \\
PI Day30 & $0.88 \pm 0.44$ & $0.83 \pm 0.44$ & \\
& $0.33 \pm 0.17$ & $0.35 \pm 0.17$ & \\
\hline GI Baseline & $1.73 \pm 0.49$ & $1.81 \pm 0.57$ & $0.19 \pm 0.06$ \\
GI Day 15 GI Day30 & $0.94 \pm 0.34$ & $0.97 \pm 0.57$ & \\
& $0.49 \pm 0.37$ & $0.48 \pm 0.36$ & $1.50 \pm 0.51$ \\
\hline PD Baseline PD Day 15 & $3.98 \pm 0.90$ & $3.91 \pm 0.89$ & \\
PD Day30 & $3.47 \pm 0.98$ & $3.42 \pm 0.87$ & $3.17 \pm 0.76$ \\
\hline CAL Baseline CAL Day 15 & $2.56 \pm 0.80$ & $3.45 \pm 0.91$ & $0.00 \pm 0.00$ \\
CAL Day30 & $3.36 \pm 0.71$ & $3.37 \pm 0.88$ & \\
& $3.22 \pm 0.66$ & $3.26 \pm 0.86$ & \\
\hline
\end{tabular}

TABLE (2) Comparison between biological mediators:

\begin{tabular}{|c|c|c|c|}
\hline Biological mediators & (SRP+Vibramycin) Group1 & (SRP) 2 Group & $\begin{array}{c}3 \text { Group } \\
\text { (Healthy Control) }\end{array}$ \\
\hline Nitrite Baseline Nitrite Day15 & $0.80 \pm 5.73$ & $0.54 \pm 5.96$ & $0.22 \pm 1.53$ \\
Nitrite Day30 & $0.26 \pm 2.70$ & $0.82 \pm 4.64$ & \\
& $0.19 \pm 1.65$ & $0.85 \pm 2.66$ & $0.18 \pm 1.05$ \\
\hline Nitrate Baseline Nitrate Day15 & $0.25 \pm 2.73$ & $0.55 \pm 2.91$ & \\
Nitrate Day30 & $0.18 \pm 1.75$ & $0.74 \pm 2.31$ & $0.37 \pm 2.57$ \\
& $0.13 \pm 1.17$ & $0.29 \pm 1.76$ & \\
\hline NO Baseline NO Day15 & $0.80 \pm 8.46$ & $0.88 \pm 8.87$ & \\
NO Day30 & $0.34 \pm 4.44$ & $1.32 \pm 6.95$ & \\
& $0.36 \pm 2.93$ & $0.96 \pm 4.42$ & \\
\hline
\end{tabular}

\section{DISCUSSION}

Several studies have investigated the role of NO in the progression of periodontal diseases. Chen et al. revealed an increase in NO expression in periodontitis where as Lohianai et al. showed that enhanced formation of NO played a significant role in the pathogenesis of periodontitis ${ }^{(\mathbf{1 5})}$. The source of anti-oxidant defence system against reactive oxygen species as nitric oxide may be endogenous as Vitamin A, B, C and E, carotene, and enzymatic oxidants such as superoxide dismutase, catalase, and myeloperoxidase or exogenous as drugs ${ }^{(16)}$. Vibramycin scavenges radicals and reduces oxidative stress. It is used as antioxidant drug. Whiteman and Halliwell demonstrated that doxycycline protected against peroxynitrite-induced degradation 
of $\alpha 1$-antiproteinas ${ }^{(17)}$. Another investigations by Yagan et al. suggested that doxycycline decreased the oxidative stress index of gingival tissue in rats with periodontitis ${ }^{(18)}$. The flow of gingival crevicular fluid is an important determinant for the status of periodontal tissues. Reports have found that several crevicular biomarkers could be used to detect and/ or predict periodontal disease activity $^{(\mathbf{1 9})}$. It has been previousely found by Ali et al. that nitrite and nitrate levels( metabolities of nitric oxide) in gingival crevicular fluid can be used as early detection marker in periodontal inflammation $^{(20)}$. The present study employed non surgical periodontal therapy since scaling and root planning treatment approach in periodontal therapy is an efficient method to reduce the amount of calculus and biofilm bacteria attached to the subgingival root surface. It also induces beneficial changes to the periodontal tissues, as reduction of the gingival inflammation, reduction of probing pocket depth, and gain in clinical attachment ${ }^{(21)}$. Although serum has been used to evaluate the risk for an individual to develop periodontal disease and to monitor the host response to periodontal therapy, in this study measurement of nitric oxide level was performed in gingival crevicular fluid rather than serum as gingival crevicular fluid has the benefit of being closely approximated to the site of destruction and thus provide more information than markers in the serum ${ }^{(22)}$. Gingival crevicular fluid sampling offers several advantages as ease of access, atraumatic technique and enables repeated sampling at different times from the same site ${ }^{(23)}$. In the present study vibramycin has been used in adjunct to non surgical periodontal therapy in one group and the other group received only non surgical periodontal therapy in order to show the effect of doxcycyline as antioxidant to nitric oxide which is involved in pathogenesis of periodontal disease. Doxcycycline was used systemically as 100 mg oral tablet once daily for two weeks.It has many properties other than the antimicrobial. It combats oxidative stress, mop up free radicals and inhibit an excessive inflammatory response secondary to an antigenic stimulus. The present results demonstrated that group I and group II showed decrease in nitric oxide level that where statisticaly significant when compared to baseline.When comparing the two groups the decrease in nitric oxide level were more favorable in group I as compared to group II at each follow up period.

Furthermore, statistical analysis of data showed non significant differences in the clinical parameters between the two groups at $\mathrm{Day}_{30}$ after treatment as regard GI and PI. This may be attributed to the comprehensive treatment modality and oral hygiene maintenance that offered coverage of the major etiologic factors of both groups. The present study showed a reduction of GI after day ${ }_{15}$ and day $_{30}$ in group 1. The exact explanation of these findings may be attributed to the anti-inflammatory effect of doxcycycline and its ablility to scavenge $\operatorname{ROS}^{(24)}$. A significant decrease in PD and gain in CAL were found within both groups (group 1 and group 2) at day ${ }_{15}$ and day $_{30}$ compared to baseline. When comparing group 1 and group 2, the decrease in PD was more favorable in group 1 as compared to group 2 at follow up period day d $_{30}$. This is attributed to anti-collagenase property of tetracycline ${ }^{(25)}$. In the present study, nitric oxide level was reduced in both groups (group1 and group 2) after day ${ }_{15}$ and day ${ }_{30}$.

There was insignificant difference between group 1 and group 2 at baseline, on the other hand group 1 showed more reduction in the nitric oxide level than group 2 at follow up period day ${ }_{15}$ and day d $_{30}$. Group 1 showed insignificant difference in nitric oxide level when compared to group 3 (healthy control) at day $_{30}$. The tenable explanation of these findings is attributed to the antioxidant effect of doxcycycline. The anti-proteolytic property, doxcycycline inhibition of neutrophil collagenase may also prevent other proteolytic events because neutrophil collagenase (MMP-8) as well as neutrophil-derived reactive oxygen species, i.e., hydrogen peroxide, and nitric oxide can degrade and inactivate $\alpha-1$ proteinase inhibitor ${ }^{(26)}$. 


\section{REFERENCES}

1. FLEMMIG, T. F. 1999. Periodontitis. Ann Periodontol, 4, $32-8$.

2. KINANE, D. F. 1999. Periodontitis modified by systemic factors. Annals of Periodontology, 4, 54-63.

3. TONETTI, M. S. \& MOMBELLI, A. 1999. Early-onset periodontitis. Annals of Periodontology, 4, 39-52.

4. CANAKCI, C., CICEK, Y. \& CANAKCI, V. 2005. Reactive oxygen species and human inflammatory periodontal diseases. Biochemistry (Moscow), 70, 619628.

5. WADDINGTON, R., MOSELEY, R. \& EMBERY, G. 2000. Periodontal Disease Mechanisms: Reactive oxygen species: a potential role in the pathogenesis of periodontal diseases. Oral diseases, 6, 138-151.

6. WEI, D., ZHANG, X. L., WANG, Y. Z., YANG, C. X. \& CHEN, G. 2010. Lipid peroxidation levels, total oxidant status and superoxide dismutase in serum, saliva and gingival crevicular fluid in chronic periodontitis patients before and after periodontal therapy. Australian Dental Journal, 55, 70-78.

7. LAPPIN, D. F., KJELDSEN, M., SANDER, L. \& KINANE, D. F. 2000. Inducible nitric oxide synthase expression in periodontitis. J Periodontal Res, 35, 369-73.

8. UĞAR-ÇANKAL, D. \& OZMERIC, N. 2006. A multifaceted molecule, nitric oxide in oral and periodontal diseases. Clinica chimica acta, 366, 90-100.

9. PEROZINI,C.,CHIBEBE, P.C.,LEãO,M.V.P., DA SILVA QUEIROZ, C. \& PALLOS, D. 2010. Gingival crevicular fluid biochemical markers in periodontal disease: A crosssectional study. Quintessence International, 41.

10. GREENSTEIN, G. 1997. Contemporary interpretation of probing depth assessments: diagnostic and therapeutic implications. Aliterature review. Journal of periodontology, 68, 1194-1205.

11. GUENTSCH, A., KRAMESBERGER, M., SROKA, A., PFISTER, W., POTEMPA, J. \& EICK, S. 2011. Comparison of gingival crevicular fluid sampling methods in patients with severe chronic periodontitis. Journal of periodontology, 82, 1051-1060.

12. CAStro, M. M., RIZZI, E., CERON, C. S., GUIMARAES, D. A., RODRIGUES, G. J., BENDHACK, L. M., GERLACH, R. F. \& TANUS-SANTOS, J. E. 2012.
Doxycycline ameliorates $2 \mathrm{~K}-1 \mathrm{C}$ hypertension-induced vascular dysfunction in rats by attenuating oxidative stress and improving nitric oxide bioavailability. Nitric Oxide, 26, 162-168.

13. GRIFFITHS, G. S. 2003. Formation, collection and significance of gingival crevice fluid. Periodontology 2000, 31, 32-42.

14. LAMSTER, I. B. 1997. Evaluation of components of gingival crevicular fluid as diagnostic tests. Annals of Periodontology, 2, 123-137.

15. LOHINAI, Z., BENEDEK, P., FEHER, E., GYöRFI, A., ROSIVALL, L., FAZEKAS, Á., SALZMAN, A. L. \& SZABó, C. 1998. Protective effects of mercaptoethylguanidine, a selective inhibitor of inducible nitric oxide synthase, in ligature-induced periodontitis in the rat. British journal of pharmacology, 123, 353-360.

16. DAHIYA, P., KAMAL, R., GUPTA, R., BHARDWAJ, R., CHAUDHARY, K. \& KAUR, S. 2013. Reactive oxygen species in periodontitis. Journal of Indian Society of Periodontology, 17, 411 .

17. WHITEMAN, M. \& HALLIWELL, B. 1997. Prevention of peroxynitrite- dependent tyrosine nitration and inactivation of alpha1-antiproteinase by antibiotics. Free Radic Res, 26, 49-56.

18. YAĞAN, A., KESIM, S. \& LIMAN, N. 2014. Effect of low-dose doxycycline on serum oxidative status, gingival antioxidant levels, and alveolar bone loss in experimental periodontitis in rats. Journal of periodontology, 85, 478489.

19. SOUZA, S. L. S. D. \& TABA JR, M. 2004. Cross-sectional evaluation of clinical parameters to select high prevalence populations for periodontal disease: the site comparative severity methodology. Brazilian dental journal, 15, 46-53.

20. ALI, O. T., AKALIN, F. A., SAHBAZOGLU, K. B., YAMALIK, N., KILINC, K., KARABULUT, E. \& TöZUM, T. F. 2014. Nitrite and nitrate levels of gingival crevicular fluid and saliva in subjects with gingivitis and chronic periodontitis. Journal of oral \& maxillofacial research, 5 .

21. ADRIAENS, P. A. \& ADRIAENS, L. M. 2004. Effects of nonsurgical periodontal therapy on hard and soft tissues. Periodontology 2000, 36, 121-145.

22. OZMERIC, N. 2004. Advances in periodontal disease markers. Clinica Chimica Acta, 343, 1-16. 
23. MCCULLOCH, C. 1994. Collagenolytic enzymes in gingival crevicular fluid as diagnostic indicators of periodontitis. Annals of the New York Academy of Sciences, 732, 152-164.

24. WEBSTER, G. \& DEL ROSSO, J. Q. 2007. Anti-inflammatory activity of tetracyclines. Dermatol Clin, 25, 133-5,v.

25. GOLUB, L. M., RAMAMURTHY, N., MCNAMARA, T.
F., GOMES, B., WOLFF, M., CASINO, A., KAPOOR, A., ZAMBON, J., CIANCIO, S., SCHNEIR, M.\& ET

AL. 1984. Tetracyclines inhibit tissue collagenase activity. A new mechanism in the treatment of periodontal disease. J Periodontal Res, 19, 651-5.

26. MICHAELIS, J., VISSERS, M. \& WINTERBOURN, C. C. 1990. Human neutrophil collagenase cleaves $\alpha 1$ antitrypsin. Biochemical journal, 270, 809- 814. 